\title{
Physiological and Spectral Response of the Halophyte Suaeda Salsa to Salt Stress in a Coastal Wetland Area
}

\author{
Xia Lu' ${ }^{1}$, Yanqin Tian', Sen Zhang 1, ", Yuanzhi Zhang, ${ }^{2,}$, Yurong Li ${ }^{1}$, Rui Wen ${ }^{3}$, Yali Lin ${ }^{1}$, Zhihu \\ Yan $^{1}$ \\ 1. Big Data Application Center of Ocean Remote Sensing, Huaihai Institute of Technology, Lianyungang, \\ Jiangsu province, China \\ 2. National Astronomical Observatories, Key Lab of Lunar Science and Deep-exploration, Beijing, China \\ 3. Third Institute of Oceanography, Ministry of Natural Resources, Xiamen City, Fujian Province, China \\ *Correspondence: zhangsen.henan@foxmail.com (S.Z.), yuanzhizhang@hotmail.com (Y. Zhang). \\ Authors contributed to the manuscript equally.
}

\begin{abstract}
In order to understand the response mechanism between plant stress, physiological indicators and hyperspectral indices, pot experiments were conducted on Suaeda salsa seedlings collected from a coastal wetland area to reveal the effects of salt stress on the physiological indicators and reflectance spectra of Suaeda salsa at the canopy and leaf level. The Suaeda salsa seedlings were exposed to seven salt treatments of different concentrations $(0 \mathrm{mmol} / \mathrm{L}$ (control), $50 \mathrm{mmol} / \mathrm{L}, 100 \mathrm{mmol} / \mathrm{L}, 200 \mathrm{mmol} / \mathrm{L}, 300 \mathrm{mmol} / \mathrm{L}, 400 \mathrm{mmol} / \mathrm{L}$, and $600 \mathrm{mmol} / \mathrm{L}$ ) in natural conditions. The physiological indicators of plant height, fresh weight, dry weight, leaf succulence, chlorophyll content, and carotenoid content were measured, in addition to the reflectance spectra of Suaeda salsa at both the canopy and leaf level. Firstly, the effects of salt stress on the physiological indicators and reflectance spectra were analyzed by the qualitative and quantitative methods. Then, physiological indicators sensitive to salt stress were further retrieved. Afterwards hyperspectral indices such as $a / b$ and $((a-b) /(a+b))$ sensitive to salt stress were also extracted by one-way analysis of variance (ANOVA) and Student-Newman-Keuls (S$\mathrm{N}-\mathrm{K}$ ) comparison test. Our results showed that plant height, root length, leaf succulence, biomass, Chl-a, and Chl-b were sensitive to salt stress, while carotenoids (Car) and relative water content on the root were not significantly affected by salt stress. At the salt concentration of $200 \mathrm{mmol} / \mathrm{L}$, plant height, biomass, relative water content, leaf succulence peaked. With enhanced salt stress, physiological indicators decreased. The first-order derivative spectral reflectance has the highest correlation with salt stress, compared to the control. The spectral index most sensitive to the salt stress at the canopy level is ( $\left.\mathrm{D}_{903}-\mathrm{D}_{851}\right) /\left(\mathrm{D}_{903}+\mathrm{D}_{851}\right)$, for which the multiple determination coefficient $\left(\mathrm{r}^{2}\right)$ is 0.9216 . While the most sensitive spectral index to the salt stress is $\left(\mathrm{D}_{442}-\mathrm{D}_{667}\right) /\left(\mathrm{D}_{442}+\mathrm{D}_{667}\right)$ at the leaf level, for which the $\mathrm{r}^{2}$ is -0.898 . In summary, the results indicated that there exists the quantitative relationship between the physiological indicators and spectra reflectance under salt stress and hyperspectral plant indices can effectively estimate the degree of salt stress. The inconsistency between the diagnostic hyperspectral plant indices at the canopy and leaf levels may be caused by the observation conditions, canopy structure.
\end{abstract}

Keywords: physiological indicators; reflectance spectra; Suaeda salsa; salt stress; coastal wetland 


\section{Introduction}

Coastal wetlands are one of the most important ecosystem types, and they are also an important resource for the economic and social development of coastal areas. As a result, coastal wetlands play a significant role in the development of offshore fisheries and the protection of endangered species [1]. However, in recent decades, the unreasonable exploitation and utilization of coastal biotic resources, driven by the pursuit of economic development, has resulted in degradation of the ecological environment of coastal wetlands, putting vegetation and wildlife habitats at great risk [2,3]. Soil salinization is one of the most important factors for the degraded ecological environment in coastal wetlands [4]. In recent years, the ecological restoration of coastal wetland by the use of halophyte vegetation has become a hot topic [5]. Suaeda salsa is one of the most important salt-tolerant plants used for restoring the ecological environment in coastal wetlands [6]. Suaeda salsa can not only absorb a large amount of soil salt and store this in its thick leaves, but it can also accumulate and absorb heavy metals from the soil, which has the effect of improving and restoring damaged coastal wetland ecosystems [7-9]. Furthermore, Suaeda salsa can adapt to the different water and salt environments in the intertidal zone and the upper tidal zone by adjusting its morphological characteristics and biomass allocation, thus maintaining population stability and improving salinized soil [10].

Actually, water level and soil salinity are important limiting factors for the growth of halophytic vegetation [11]. Some researchers have focused on the relationships between the growth and population distribution of Suaeda salsa and the salt stress and chemical elements in the soil [12-17]. However, research on the morphological and physiological response of halophyte plants to both salt and water stress is relatively rare [11].

Hyperspectral sensors have many narrow bands, which can discriminate some critical spectral differentials in detail. Hyperspectral reflectance is thus a powerful tool for the monitoring of environmental stress and plant growth [17]. A number of studies have been conducted on the application of the hyperspectral remote sensing technique to the classification of halophyte plants [18], the response of hyperspectral indices to soil chemical properties [19], spectral characteristics analysis for halophyte plants [20], and the biomass estimation of Suaeda salsa [21,22].

Viewed from the new perspective of combining spectral characteristics with ecological health, the effects of salt stress on the physiological indicators and reflectance spectra of Suaeda salsa were investigated in this study. The objectives of this study were: 1) to investigate the effects of salt stress on the physiological indicators of Suaeda salsa and to determine the physiological indicators that are sensitive to salt stress; 2) to analyze the effect of salt stress on the canopy and leaf spectra; and 3) to identify the spectral characteristic variables that are sensitive to salt stress.

\section{Materials and methods}

\subsection{Site description}

Suaeda salsa seedlings were collected in the Dafeng Milu National Nature Reserve ( $32^{\circ} 59^{\prime}-$ $33^{\circ} 03^{\prime} \mathrm{N}, 120^{\circ} 47^{\prime}-120^{\circ} 53^{\prime} \mathrm{E}$ ), Jiangsu province, China (Fig. 1), which is the largest elk nature reserve in the world. The climate of the study area belongs to the transition zone between the 
subtropics and the warm temperate zone. The humidity in the area is relatively high. The mean precipitation is $1,068 \mathrm{~mm} /$ year and the average annual temperature is $14.1^{\circ} \mathrm{C}$. The soil type is mainly coastal saline soil in meadows and tidal beaches. The dominant plant species are Spartina alterniflora, Suaeda salsa, Zoysia macrostachya, Phragmites australis, and Imperata cylindrica. The total area of the national reserve is about $780 \mathrm{~km}^{2}$, which is divided into a core zone, a buffer zone, and an experimental zone. The core zone is also divided into three zones. In the first and second zones, the elks are kept in captivity, while in the third zone, the elks live in a "wild pastoral area" [23].
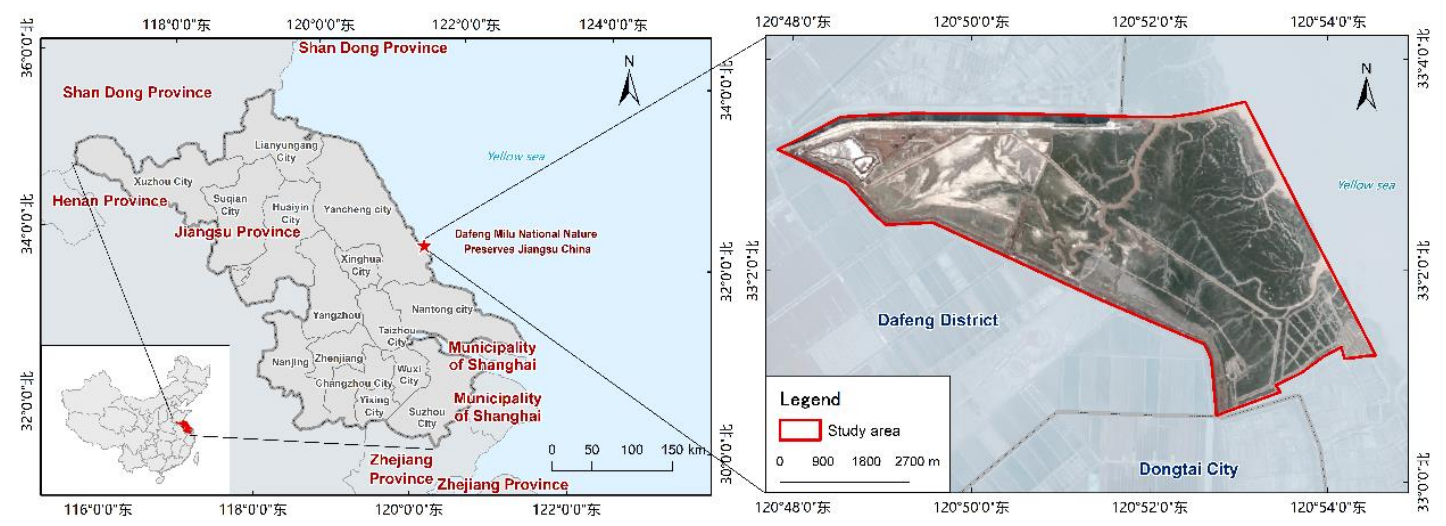

Figure 1. Dafeng Milu National Nature Reserve

\subsection{Experimental design}

Suaeda salsa seedlings with similar height $(13-15 \mathrm{~cm} \pm 0.5 \mathrm{~cm}$ for plant height, $5-8 \mathrm{~cm} \pm$ $0.5 \mathrm{~cm}$ for root length) were collected from the experimental site. The plants were washed, divided into 21 groups, and transplanted into plastic pots $(18.5 \mathrm{~cm}$ in diameter and $24.5 \mathrm{~cm}$ in height) filled with $7.5 \mathrm{~kg}$ air-dried sand. After 2 weeks when plant growth conditions tended to be healthy and stable, the experiments began with seven salinity treatments. Salinity was controlled by adding $\mathrm{NaCl}$ to Hoagland's hydroponic nutrient solution. The following concentrations of $\mathrm{NaCl}$ were applied: control (Hoagland's nutrient solution only); $50 \mathrm{mmol} / \mathrm{L}$, $100 \mathrm{mmol} / \mathrm{L}$, and $200 \mathrm{mmol} / \mathrm{L}$ (low salinity, LS); $300 \mathrm{mmol} / \mathrm{L}$ and $400 \mathrm{mmol} / \mathrm{L}$ (medium salinity, MS); and $600 \mathrm{mmol} / \mathrm{L}$ (high salinity, HS) [24].

The 21 pots were divided into seven sets according to the salinity treatment, with each set being made up of three plants. After 15 days, the plants treated with the $600 \mathrm{mmol} / \mathrm{L} \mathrm{NaCl}$ solution began to wither.

\subsection{Physiological indicator measurements}

During the culture period, the plant height was measured once every week. At the end of the experiments, the harvested plants were removed and the sand and dust were washed off with distilled water. The plants were then dried with absorbent paper. The fresh weight (FW) above ground and the FW in the roots were determined for each plant. The plant samples were then oven dried at $105^{\circ} \mathrm{C}$ for $10 \mathrm{~min}$ and then dried at $80^{\circ} \mathrm{C}$ to constant weight. The dry weight (DW) was then measured. Based on the FW and DW measurements, the degree of leaf succulence was computed by the ratio of FW to DW.

About $0.5 \mathrm{~g}$ of fresh leaf of Suaeda salsa was collected and crushed from each plant, and 
then extracted with $90 \%$ acetone for $24 \mathrm{~h}$. For each salinity level, there were three plants. The absorbency of the extraction solution at $665 \mathrm{~nm}, 649 \mathrm{~nm}$, and $470 \mathrm{~nm}$ was measured by the use of a spectrophotometer (Hitachi U-2001, Hitachi Ltd, Japan). The chlorophyll a content (chl-a), the chlorophyll b content (chl-b), the total chlorophyll content (chl $)$, and the carotenoid content (Ck) were then calculated by the use of Eqs. (1)-(4) [11]:

$$
\begin{gathered}
c h l-a=13.95 A_{665}-6.88 A_{649} \\
c h l-b=24.96 A_{649}-7.32 A_{665} \\
C_{k}=\left(1000 A_{470}-2.05 \operatorname{chl} l-a-114.8 \operatorname{chl}-b\right) / 245 \\
c h l_{T}=\operatorname{chl}-a+c h l-b=18.08 A_{649}+6.63 A_{665}
\end{gathered}
$$

where chl-a and chl-b are the chlorophyll a and b content, respectively; $\mathrm{Ck}$ is the carotenoid content; chl is the total chlorophyll content; and A is the absorbency of the extraction solution.

\subsection{Reflectance spectra measurements at the canopy and leaf level}

All of the canopy reflectance measurements were carried out using an SVC (Spectra Vista Corporation) HR-1024i field-portable spectroradiometer (SVC Inc., USA). This spectrometer covers the ultraviolet, visible, and near-infrared wavelengths from $350 \mathrm{~nm}$ to $2500 \mathrm{~nm}$. The hyperspectral resolution is less than $3.5 \mathrm{~nm}, 9.5 \mathrm{~nm}$, and $6.5 \mathrm{~nm}$, respectively, in the ranges of $350 \mathrm{~nm}$ to $1000 \mathrm{~nm}, 1000 \mathrm{~nm}$ to $1850 \mathrm{~nm}$, and $1850 \mathrm{~nm}$ to $2500 \mathrm{~nm}$. The measurements of canopy reflectance spectra were performed from a height of $40 \mathrm{~cm}$ above the canopy with $25^{\circ}$ field-ofview fiber optics between 10:00 am and 14:00 pm (Beijing time) on a sunny day. The scan time of the spectral measurement for each pot was $5 \mathrm{~s}$, and the average reflectance spectra of 10 measurements was taken as the final spectrum of each pot. The reflectance spectra of Suaeda salsa at the leaf level were measured using a blade holder with $25^{\circ}$ field-of-view fiber optics.

\subsection{Data Analysis}

\subsubsection{Physiological data analysis}

A one-way analysis of variance (ANOVA) was conducted in SPSS 23.0 (SPSS Inc., Chicago, IL, USA) to determine the effects of the different $\mathrm{NaCl}$ treatment groups on the physiological indicators. A Student-Newman-Keuls (S-N-K) comparison test was also performed to determine if the differences between individual treatments were significant $(\mathrm{p}<0.01)$. The graphs were created in Excel 2013 and the data were represented by the means of three measurements and the standard deviation (SD).

\subsubsection{Preprocessing of the spectral reflectance}

The hyperspectral reflectance spectra of Suaeda salsa at the canopy level were first preprocessed, including deleting the abnormal spectral data, resampling the spectral data, and merging the sig file for the multi-time spectral data using the SVC HR-1024i software. The noisy bands ranging from 350 to $399 \mathrm{~nm}$ were removed from the spectral curve of each sample, retaining the useful bands ranging from 400 to $2,500 \mathrm{~nm}$. The reflectance data were then smoothed with a five-point moving average filter to reduce the instrumental and 
environmental noise for the further quantitative analysis.

\subsubsection{Identification of the spectral variables sensitive to salt stress}

Firstly, the spectral reflectance difference was computed by subtracting the reflectance of the unstressed plant from that of the plants stressed by the different salt concentrations (Carter 1994). The correlation between the reflectance difference and $\mathrm{NaCl}$ concentration was then analyzed in MATLAB R2016b software. The bands and their raw and derivative reflectance where the significance $(p)$ was less than 0.01 were selected, while the bands with a strong absorption feature and a weak spectral signal ranging from 1335-1499 nm and 1770-2500 nm were removed. The absolute values of each set of reflectance differences were summed. The maximum and minimum absolute values were used to determine the numerator and denominator of the constructed ratio spectral index (RSI) and the parameters of the normalized difference spectral index (NDSI). Finally, the indices sensitive to salt stress were selected as those with a higher correlation and a higher significance level.

$$
\begin{gathered}
R S I_{i, j}=D_{j} / D_{i} \\
N D S I_{i, j}=\left(D_{j}-D_{i}\right) /\left(D_{j}+D_{i}\right)
\end{gathered}
$$

where Di and $\mathrm{Dj}$ represent the first-order differential spectral reflectance at bands $\mathrm{i}$ and $\mathrm{j}$, respectively.

\section{Results}

\subsection{Plant growth}

The mean and SD values of the physiological indicators of Suaeda salsa are listed in Table 1. Table 2 lists the ANOVA results of the effects of salinity on the physiological indicators. As shown in Table 2, the height, root length, and branch number of Suaeda salsa are significantly affected by salt stress $(p<0.01)$. As shown in Figure 2A, height, root length, and branch number increase gradually from the control to the $200 \mathrm{mmol} / \mathrm{L}$ salinity treatment, and then peak at the $200 \mathrm{mmol} / \mathrm{L}$ salinity, before decreasing gradually from the 200 to $600 \mathrm{mmol} / \mathrm{L}$ salinity levels. The lower salinity level $(0-200 \mathrm{mmol} / \mathrm{L})$ promotes the growth of Suaeda salsa, while the higher salinity level (200-600 mmol/L) depresses the growth.

As shown in Table 2, the FW and DW above ground and the FW of the roots of Suaeda salsa are significantly affected by the different $\mathrm{NaCl}$ levels $(p<0.01)$. There is no significant difference for the $\mathrm{DW}$ of roots with the different $\mathrm{NaCl}$ treatments $(\mathrm{p}>0.05)$ (Table 2; Figure 2C). As shown in Table 1, Table 2, Figure 2B, and Figure $2 \mathrm{C}$, the FW above ground and in the roots increases with increasing salinity, peaking at the $200 \mathrm{mmol} / \mathrm{L}$ salt level, and then decreasing. The DW above ground peaks at the $50 \mathrm{mmol} / \mathrm{L}$ salt level, while attaining a minimum value at the $600 \mathrm{mmol} / \mathrm{L}$ salt level for DW above ground and attaining a minimum value at the $400 \mathrm{mmol} / \mathrm{L}$ salt level for the DW of roots. 
Table 1. Statistical results of the physiological indicators for Suaeda salsa.

\begin{tabular}{|c|c|c|c|c|c|c|c|}
\hline Index & Control & $50 \mathrm{mmol} / \mathrm{L}$ & $100 \mathrm{mmol} / \mathrm{L}$ & $200 \mathrm{mmol} / \mathrm{L}$ & $300 \mathrm{mmol} / \mathrm{L}$ & $400 \mathrm{mmol} / \mathrm{L}$ & $600 \mathrm{mmol} / \mathrm{L}$ \\
\hline Height $(\mathrm{cm})$ & $16.83 \pm 0.64$ & $17.97 \pm 0.31$ & $18.67 \pm 0.21$ & $21.5 \pm 1.5$ & $15.33 \pm 0.15$ & $13.5 \pm 0.5$ & $12.43 \pm 0.15$ \\
\hline Root length $(\mathrm{cm})$ & $10.79 \pm 0.9$ & $13.13 \pm 0.4$ & $14.4 \pm 0.53$ & $16.9 \pm 0.17$ & $13.6 \pm 1.68$ & $9 \pm 1.00$ & $8.3 \pm 0.20$ \\
\hline Branch number & $13 \pm 1.00$ & $15 \pm 1.00$ & $16.67 \pm 1.53$ & $22 \pm 1.00$ & $14.33 \pm 1.53$ & $13 \pm 1.00$ & $10 \pm 1.00$ \\
\hline Leaf succulence & $4.54 \pm 0.19$ & $3.58 \pm 0.44$ & $6.82 \pm 0.27$ & $13.83 \pm 0.77$ & $4.95 \pm 1.00$ & $6.21 \pm 0.34$ & $4.85 \pm 1.57$ \\
\hline FW above ground (g) & $34.48 \pm 0.43$ & $40.77 \pm 0.64$ & $45.35 \pm 0.27$ & $49.82 \pm 1.08$ & $27.49 \pm 2.49$ & $21.5 \pm 0.2$ & $13.8 \pm 1.27$ \\
\hline DW above ground (g) & $7.61 \pm 0.32$ & $11.51 \pm 1.47$ & $6.66 \pm 0.3$ & $3.61 \pm 0.15$ & $5.64 \pm 0.64$ & $3.47 \pm 0.21$ & $2.99 \pm 0.68$ \\
\hline FW of roots $(\mathrm{g})$ & $5.95 \pm 0.35$ & $7.55 \pm 0.33$ & $7.89 \pm 0.25$ & $9.67 \pm 0.2$ & $6.83 \pm 0.61$ & $4.67 \pm 0.51$ & $3.58 \pm 0.65$ \\
\hline DW of roots $(\mathrm{g})$ & $1.28 \pm 0.15$ & $1.34 \pm 0.36$ & $1.28 \pm 0.59$ & $0.74 \pm 0.42$ & $1 \pm 0.23$ & $0.62 \pm 0.19$ & $0.65 \pm 0.04$ \\
\hline Chl-a (mg/L) & $2.8 \pm 0.86$ & $3.37 \pm 0.47$ & $2.51 \pm 0.75$ & $2.4 \pm 0.43$ & $2.2 \pm 0.17$ & $2.52 \pm 0.4$ & $1.73 \pm 0.74$ \\
\hline Chl-b (mg/L) & $0.85 \pm 0.27$ & $1.12 \pm 0.5$ & $0.77 \pm 0.23$ & $0.73 \pm 0.13$ & $0.64 \pm 0.08$ & $0.71 \pm 0.1$ & $0.53 \pm 0.22$ \\
\hline Chl-a+b (mg/L) & $3.65 \pm 1.12$ & $4.49 \pm 0.88$ & $3.28 \pm 0.97$ & $3.13 \pm 0.55$ & $2.85 \pm 0.24$ & $3.23 \pm 0.5$ & $2.26 \pm 0.96$ \\
\hline Car (mg/L) & $0.85 \pm 0.28$ & $0.78 \pm 0.11$ & $0.63 \pm 0.17$ & $0.62 \pm 0.15$ & $0.57 \pm 0.05$ & $0.64 \pm 0.09$ & $0.48 \pm 0.22$ \\
\hline
\end{tabular}

The values are the means $( \pm \mathrm{SD})$ of three measurements.

Table 2. Statistical results of the one-way ANOVA analysis results for Suaeda salsa.

\begin{tabular}{lll}
\hline Index & F & Sig. \\
\hline Height $(\mathrm{cm})$ & 66.43 & $0.000^{* *}$ \\
Root length $(\mathrm{cm})$ & 38.74 & $0.000^{* *}$ \\
Branch number & 30.81 & $0.000^{* *}$ \\
Leaf succulence & 55.84 & $0.000^{* *}$ \\
FW above ground $(\mathrm{g})$ & 371.73 & $0.000^{* *}$ \\
DW above ground $(\mathrm{g})$ & 58.44 & $0.000^{* *}$ \\
FW of roots $(\mathrm{g})$ & 63.98 & $0.000^{* *}$ \\
DW of roots $(\mathrm{g})$ & 2.78 & 0.054 \\
Chl-a (mg/L) & 3.25 & $0.032^{*}$
\end{tabular}




\begin{tabular}{lcc}
\hline Chl-b $(\mathrm{mg} / \mathrm{L})$ & 2.92 & $0.046^{*}$ \\
$\mathrm{Chl}-\mathrm{a}+\mathrm{b}(\mathrm{mg} / \mathrm{L})$ & 3.37 & $0.029^{*}$ \\
Car $(\mathrm{mg} / \mathrm{L})$ & 2.68 & 0.060 \\
\hline$\left.{ }^{*} p<0.05 ;{ }^{* *} p<0.01.\right)$ & &
\end{tabular}

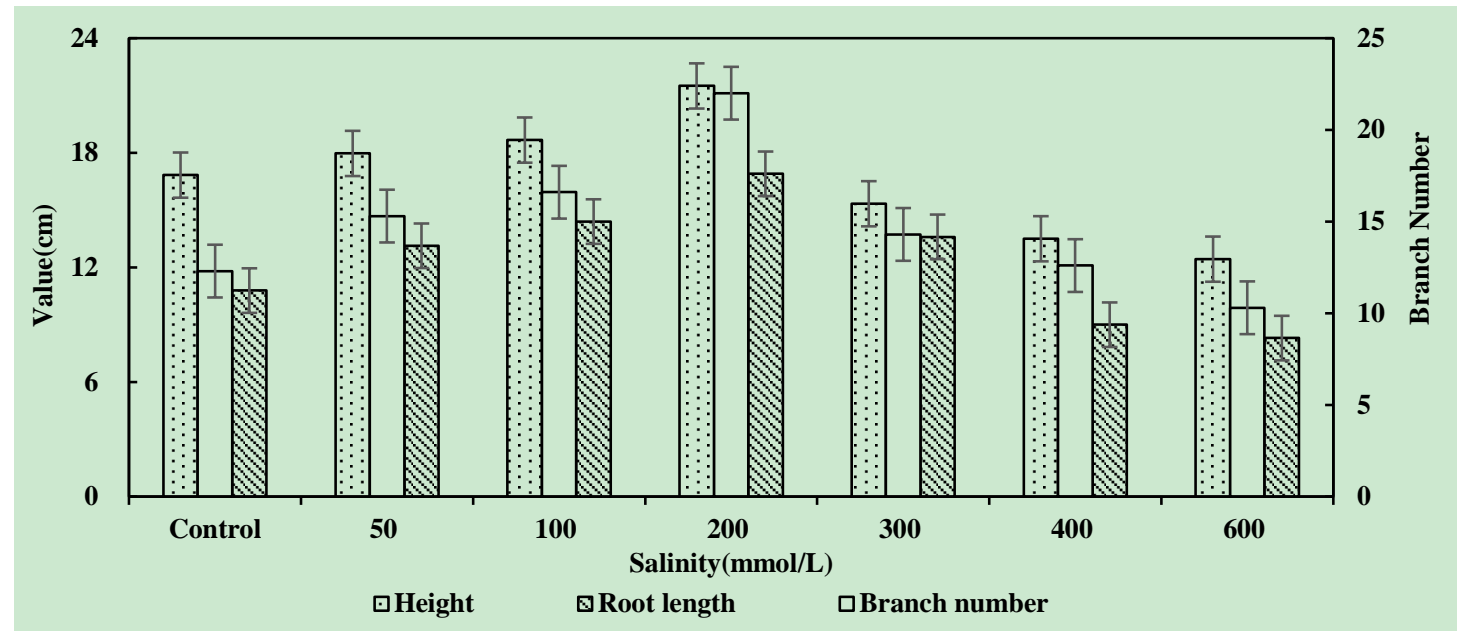

(A)

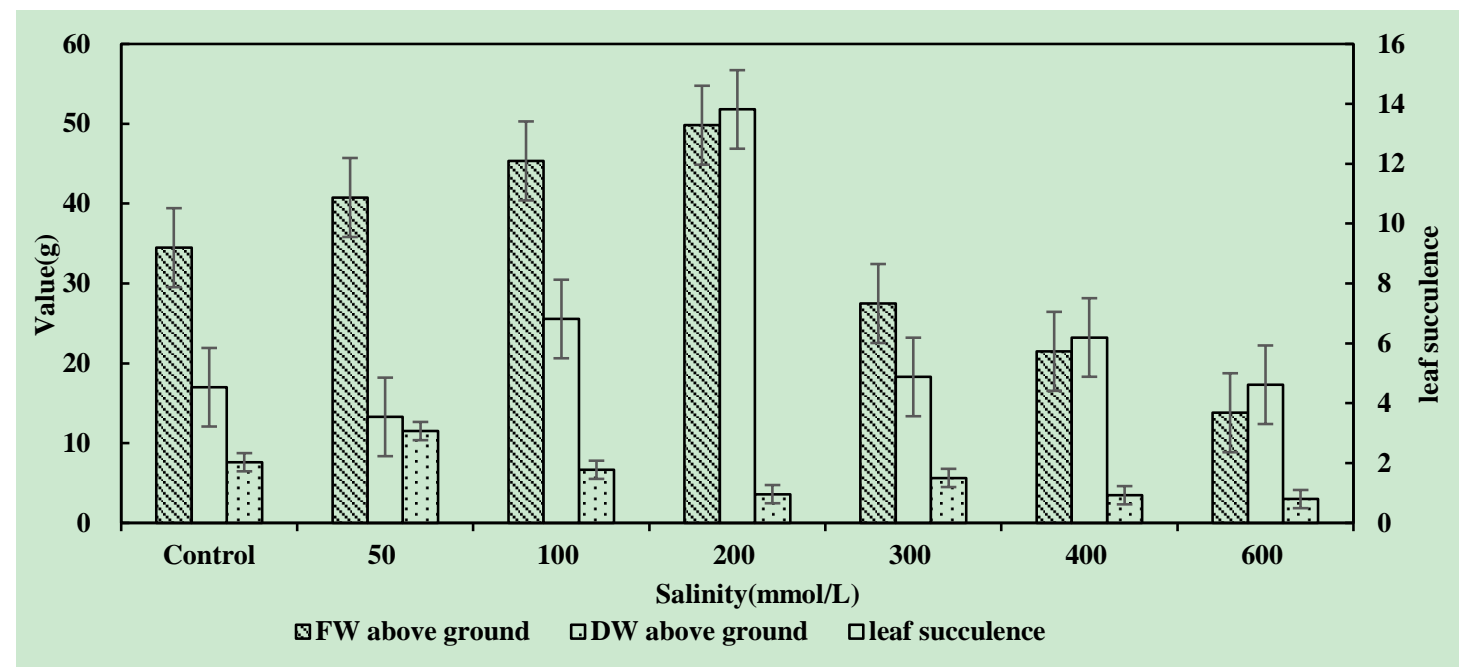

(B) 


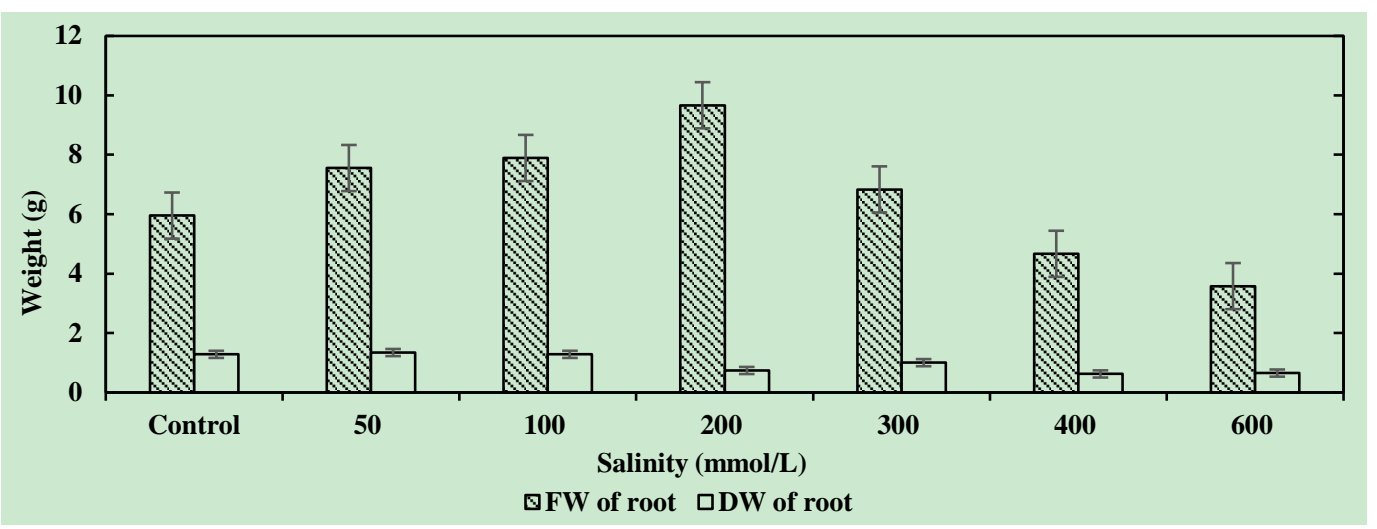

(C)

Figure 2. Effects of salt stress on the height, fresh weight (FW), and dry weight (Dw) of Suaeda salsa

\subsection{Leaf pigment content}

We investigated the changes in photosynthetic pigment contents in the salt-stressed leaves. As shown in Table 2, the chl-a content, chl-b content, and total chlorophyll content of Suaeda salsa are significantly affected by the different salinity levels $(p<0.05)$. However, there is no significant difference in the carotenoid content of Suaeda salsa with the different $\mathrm{NaCl}$ treatments ( $p>0.05$ ) (Table 2; Figure 3). As shown in Figure 3, the chl-a content, chl-b content, and total chlorophyll content of Suaeda salsa peak at the $50 \mathrm{mmol} / \mathrm{L}$ salt level, whereas the carotenoid content of Suaeda salsa peaks at the control group level.

Based on the above analysis, we conclude that the sensitive physiological indicators of Suaeda salsa are height, root length, branch number, FW above ground, DW above ground, leaf succulence, FW of roots, chl-a content, chl-b content, and total chlorophyll content.

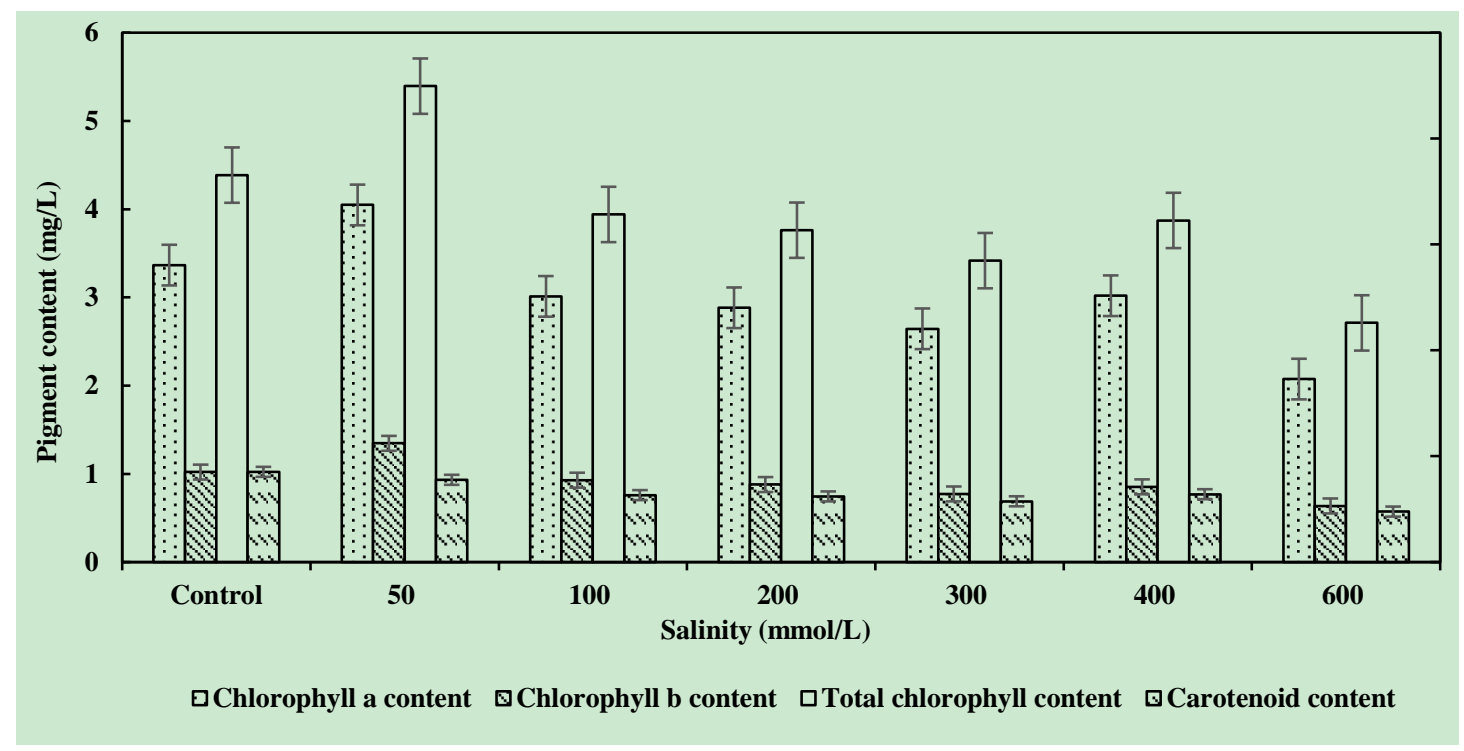

Figure 3. Effects of salt stress on the pigment contents of Suaeda salsa 


\subsection{Reflectance spectra response of Suaeda salsa to salt stress}

\subsubsection{Reflectance spectra response of Suaeda salsa at the canopy level to salt stress}

The canopy reflectance of Suaeda salsa (Figure 4) under different salt stress levels shows reflectance differences between the salt treatments that are significantly different at certain wavelengths. Higher raw reflectance for the $600 \mathrm{mmol} / \mathrm{L} \mathrm{NaCl}$ concentration and control for the Suaeda salsa plant occurs in the 400-680 nm spectral region. In addition, the canopy spectra for the $600 \mathrm{mmol} / \mathrm{L}$ salt stress level exhibits a lower raw reflectance in the 740-1,000 nm spectral region than under the other salinity stress levels.

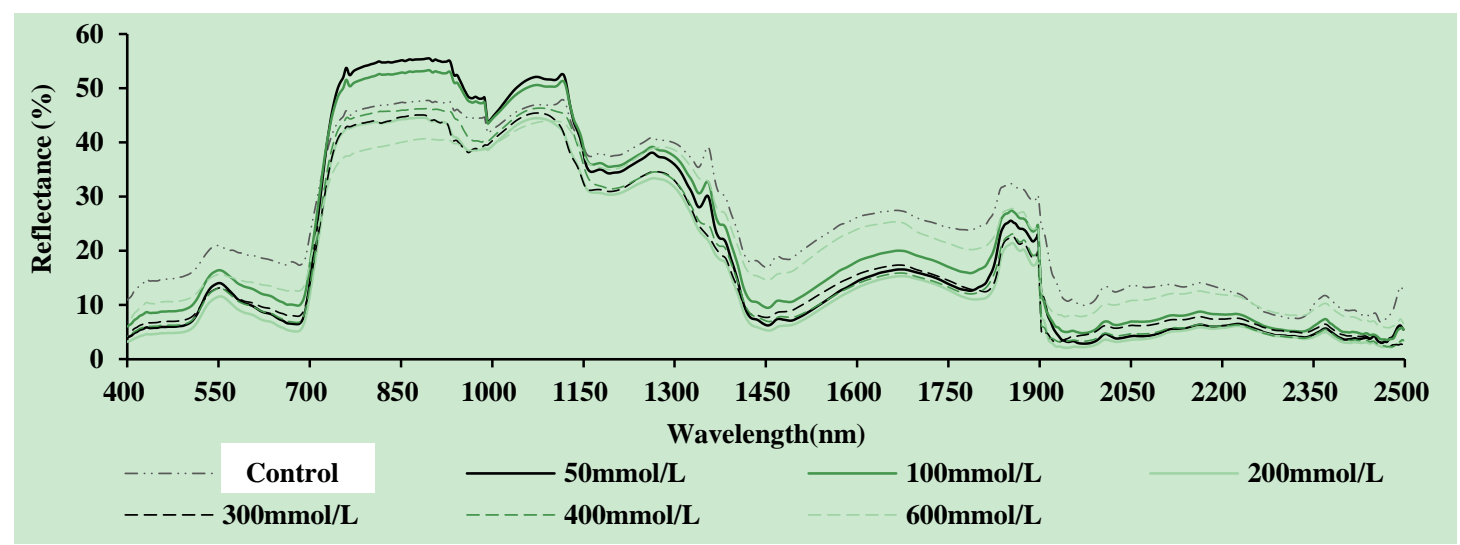

Figure 4. Effects of salt stress on the canopy reflectance spectral curves of Suaeda salsa

\subsubsection{Reflectance spectra response of Suaeda salsa at the leaf level to salt stress}

It can be seen that under different salt stress levels, the spectral reflectance of Suaeda salsa at the leaf level is not the same as that at the canopy level, in certain wavelengths (Figure 5). In the spectral range of $400-680 \mathrm{~nm}$, the spectral reflectance under the $50 \mathrm{mmol} / \mathrm{L} \mathrm{NaCl}$ concentration is basically consistent with the spectral reflectance without salt stress. The spectral reflectance of the leaves increases with the increase of the $\mathrm{NaCl}$ concentration. At the $400 \mathrm{mmol} / \mathrm{L} \mathrm{NaCl}$ concentration, the spectral reflectance of the leaves of Suaeda salsa reaches a maximum. In addition, the reflectance difference in the $740-1000 \mathrm{~nm}$ wavelength is particularly obvious, although the reflectance under the control group is still consistent with that at the $50 \mathrm{mmol} / \mathrm{L} \mathrm{NaCl}$ concentration. However, the spectral reflectance of the leaves is the highest under the salt stress of $100 \mathrm{mmol} / \mathrm{L}$. The leaf spectral reflectance ranking from high to low is: $100 \mathrm{mmol} / \mathrm{L}, 400 \mathrm{mmol} / \mathrm{L}, 200 \mathrm{mmol} / \mathrm{L}, 300 \mathrm{mmol} / \mathrm{L}$, and $600 \mathrm{mmol} / \mathrm{L}$, respectively. 


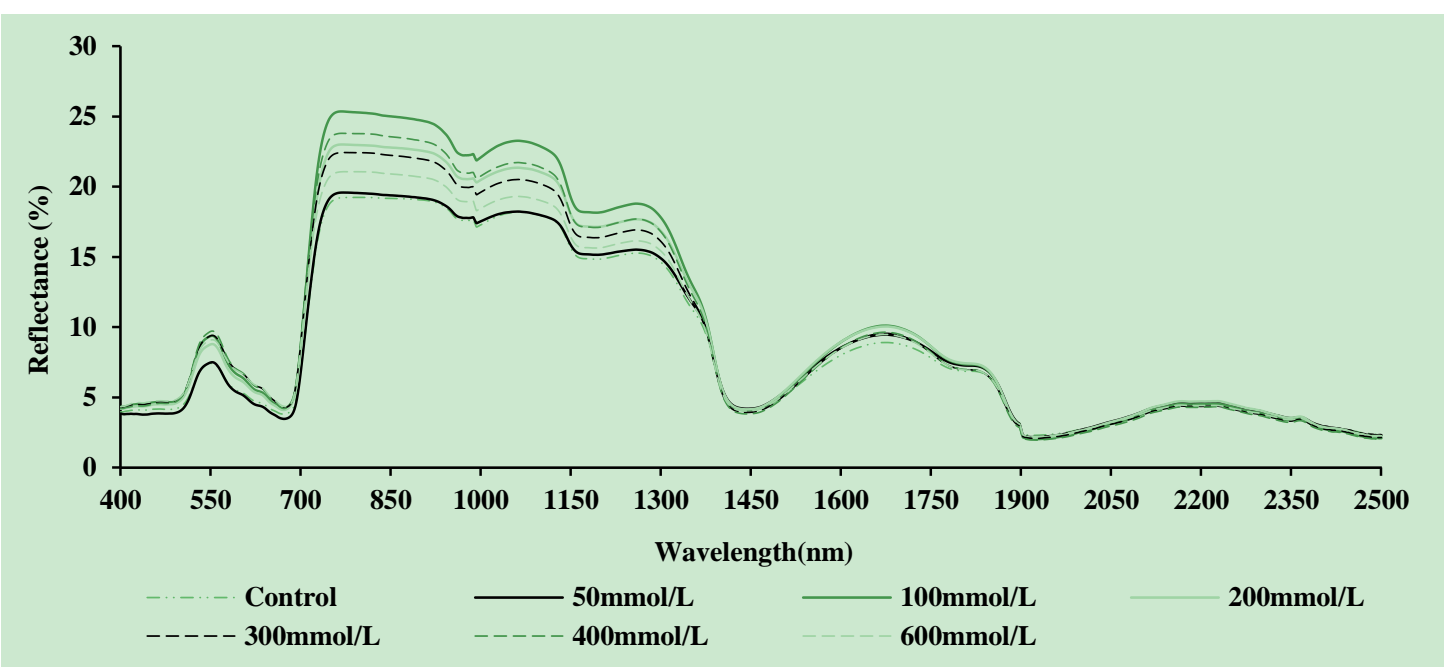

Figure 5. Effects of salt stress on the leaf reflectance spectra of Suaeda salsa

\subsection{Hyperspectral indices sensitive to salt stress}

\subsubsection{Determination of the hyperspectral indices sensitive to salt stress at the canopy level}

Soil salinity affects the growth of Suaeda salsa. In order to estimate the salt stress, the reflectance of Suaeda salsa was taken as an indirect index [27, 29]. For each salinity level, the reflectance difference (Figure 6) between the original spectra and the first-derivative spectra was calculated by subtracting the mean canopy reflectance of the non-stressed canopy from that of the salt-stressed canopy at each spectral radiometer channel [27]. The correlation coefficients (Figure 7) were then analyzed at each wavelength for the different $\mathrm{NaCl}$ levels in MATLAB R2016a. It can be seen that the original spectral reflectance difference is negatively correlated with the salinity level in the ranges of $400-1,406 \mathrm{~nm}$ and 1,688-1,961 nm, reaching a significance level of $0.05 \mathrm{in}$ the ranges of $722-895 \mathrm{~nm}, 972-973 \mathrm{~nm}$, and $980-989 \mathrm{~nm}$. In contrast, the original spectral reflectance difference is positively correlated with the salinity stress in the ranges of $1,407-1,687 \mathrm{~nm}$ and 1,962-1,996 nm. Furthermore, the absolute values of the correlation coefficients are lower than at the 400-1,406 nm and 1,688-1, $961 \mathrm{~nm}$ wavelengths. From Table 3, it can be seen that the maximum correlation coefficient is -0.818 at $734 \mathrm{~nm}$. The above analysis indicates that the mid-infrared wavebands are not sensitive to salinity stress, and it is likely that the canopy and leaf structure are primarily affecting the spectral characteristics.

There exists an obvious correlation between the first-order derivative reflectance difference and the different $\mathrm{NaCl}$ levels at the canopy level (Figure 7). In addition, the correlation coefficient curve shows large fluctuations. A very significant positive correlation $(p<0.01)$ can be observed in the ranges of 591-592 $\mathrm{nm}$ and $628-634 \mathrm{~nm}$, and a significant negative correlation $(p<0.01)$ can be observed at $974 \mathrm{~nm}$ and 1,169-1,177 nm. The highest correlation coefficient is 0.962 at 1,262 nm (Table 3). On the whole, the correlation coefficient of the first-order derivative canopy reflectance difference is generally higher than that of the original reflectance spectra. Therefore, the first-order derivative canopy spectra were selected for the subsequent processing. 


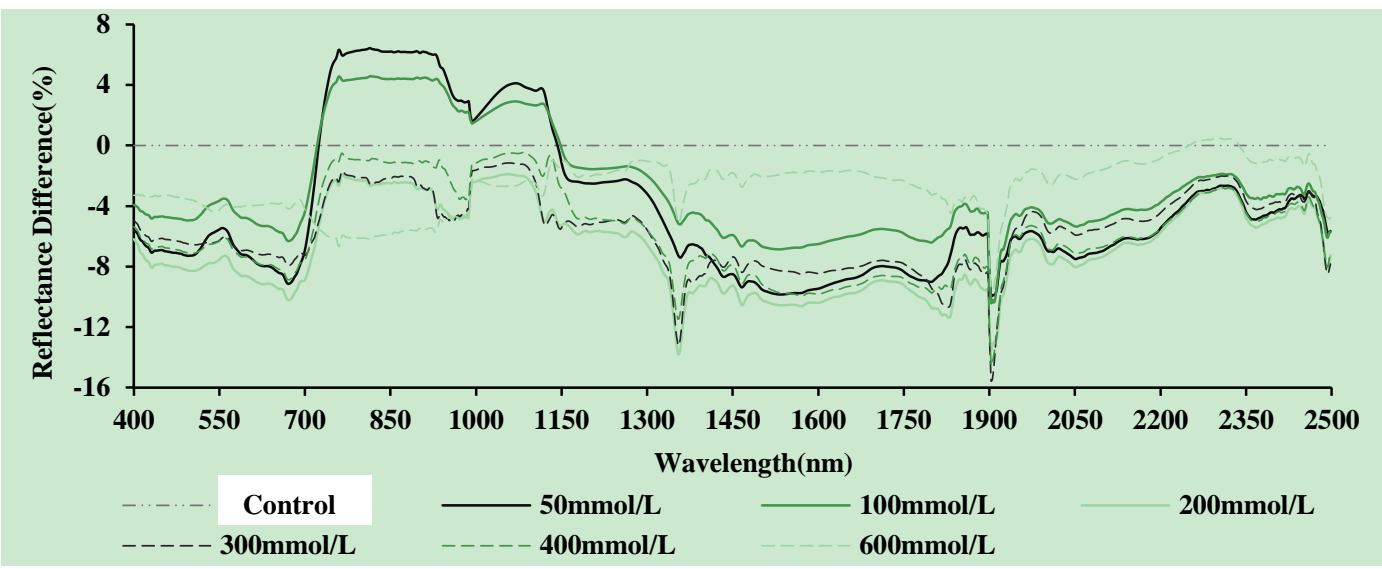

(a)

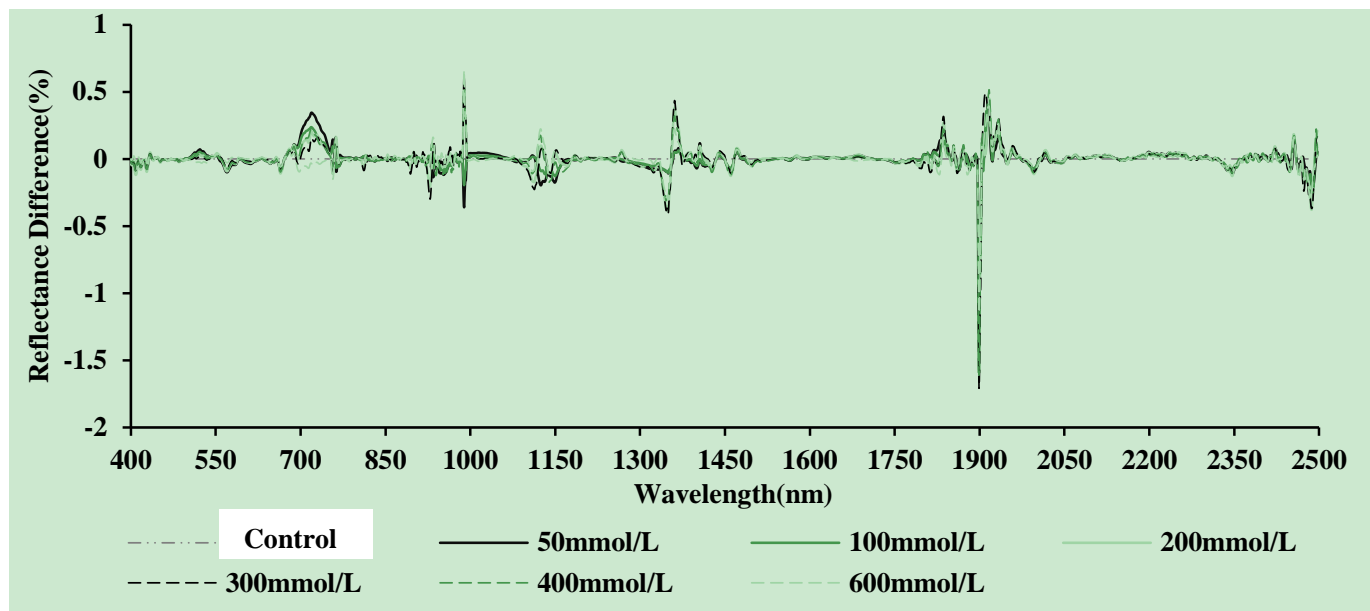

(b)

Figure 6. Reflectance difference between the original spectra (a) and the first-derivative spectra (b) for stressed vs. non-stressed leaves throughout the $400-2,500 \mathrm{~nm}$ wavelength. The differences were computed by subtracting the mean reflectance of non-stressed leaves (zero line) from that of stressed leaves. The mean values are for three measurements $(\mathrm{N}=3)$.

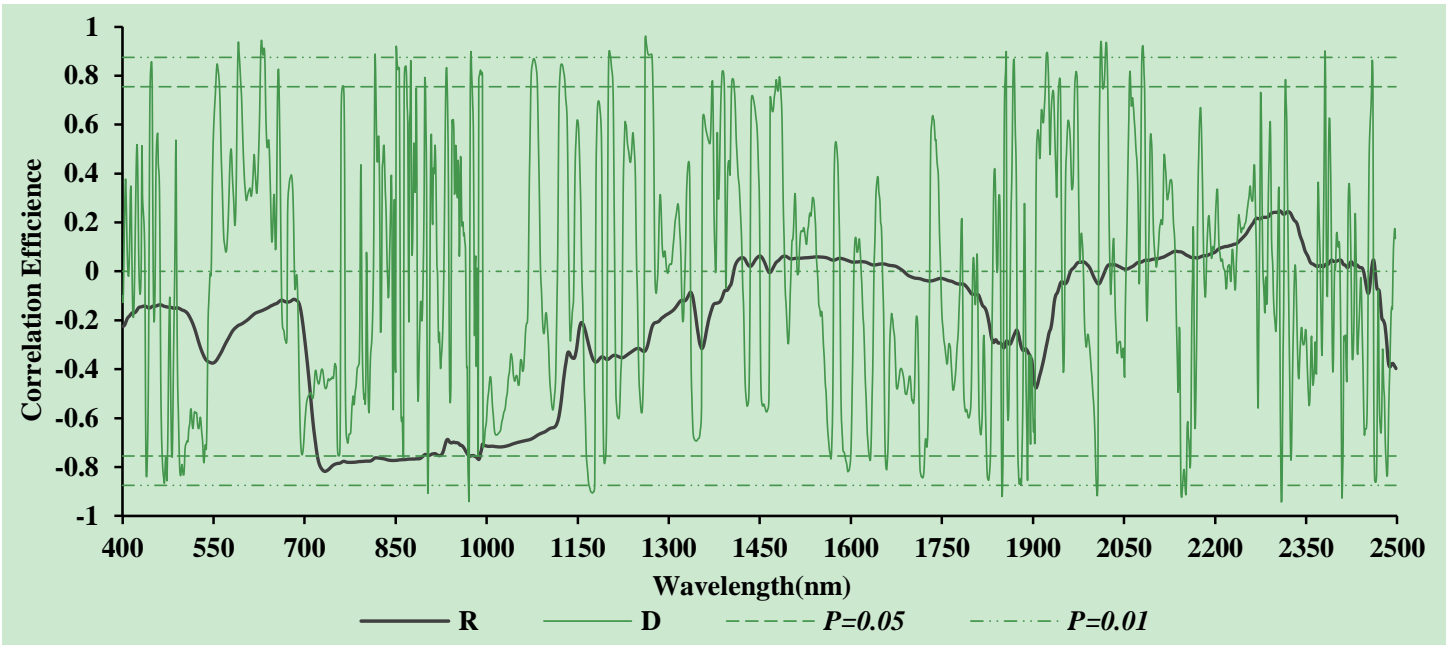


Figure 7. A plot of the correlation coefficients between the reflectance difference of the raw canopy spectra and the first-derivative spectra and salt concentration. The thick and thin lines are the curves of the reflectance difference of the original spectra and the first-derivative spectra and the salt concentration correlation coefficient, respectively.

Table 3. Wavelength ranges $(\mathrm{nm})$ for significant reflectance differences

\begin{tabular}{|c|c|c|c|c|}
\hline \multirow{2}{*}{$\begin{array}{c}\text { Spectral } \\
\text { transformatio } \\
\text { n }\end{array}$} & \multicolumn{2}{|c|}{ r_max } & \multirow[b]{2}{*}{ Number } & \multirow[b]{2}{*}{ Wavelength ranges (nm) } \\
\hline & $\begin{array}{c}\text { Wavelength } \\
(\mathbf{n m})\end{array}$ & $\mathbf{r}$ & & \\
\hline $\mathrm{R}$ & 734 & $-0.818^{*}$ & 186 & $722-895,972-973,980-989$ \\
\hline $\mathrm{D}$ & 1262 & $0.962 * *$ & 65 & $\begin{array}{c}591-592,628-634,816,851,903,971,974,1169 \\
1177,1201-1204,1261-1272,1849,1856,1880, \\
1922-1924,2005-2006,2011-2013,2020-2022, \\
2080-2082,2144-2146,2151-2152,2309-2310, \\
2381,2409\end{array}$ \\
\hline
\end{tabular}

Note: ${ }^{*} \mathrm{p}<0.05,{ }^{* *} \mathrm{p}<0.01$. These wavelength ranges were significantly different $(\mathrm{p}<0.05)$ between the reflectance difference and the salt levels, according to the Pearson's correlation analysis. Difference and correlation values were obtained from Figure 3 and 4, respectively.

The maxima (a) and minima (b) of the reflectance difference determine the parameters of the ratio vegetation index (RSI) $(a / b)$ and the normalized difference spectral index (NDSI) $((a-b) /(a+b))$. Parameters $a$ and $b$ are the maximum and the minimum of the reflectance differences which change significantly with salt stress, respectively.

Carter (1993) [29] indicated that visible rather than infrared reflectance responds most consistently to plant stress. Here, the maximum (a) and the minimum (b) of the reflectance differences are $816 \mathrm{~nm}, 903 \mathrm{~nm}, 974 \mathrm{~nm}$ and $592 \mathrm{~nm}, 628 \mathrm{~nm}, 851 \mathrm{~nm}$, respectively.

In order to retrieve the spectral indices that are sensitive to salt stress, the spectral indices were first calculated in MATLAB R2016a using the reflectance differences in the above retrieved wavelengths. The correlation between these indices and the different $\mathrm{NaCl}$ levels was then analyzed in detail. Finally, the narrow-band spectral indices that were significantly correlated $(\mathrm{p}<0.01)$ with the $\mathrm{NaCl}$ concentrations were obtained. For these spectral indices, $\mathrm{p}$ and $\mathrm{r}^{2}$ are less than 0.01 and greater than or equal to 0.80 , respectively (Table 4). As shown in Table 4, each spectral index is denoted by the correlation and significance value. The RSI indices of (R974/R592

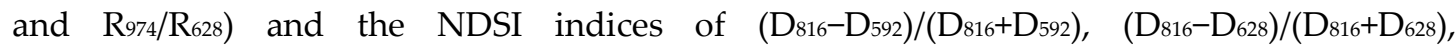
(D903-D851)/(D903+D851), ( $\left.\mathrm{D}_{974}-\mathrm{D}_{592}\right) /\left(\mathrm{D}_{974}+\mathrm{D}_{592}\right)$ are the final indices that are sensitive to salt stress (Table 4). A further spectral index ( $\left.\mathrm{D}_{974}-\mathrm{D}_{628}\right) /\left(\mathrm{D}_{974}+\mathrm{D}_{628}\right)$ correlates most significantly to the salt stress, with the highest correlation coefficient. 
Table 4. Canopy spectral indices that were tested for significant $(p<0.05)$ correlation with the salt concentration

\begin{tabular}{cccccc}
\hline Spectral index & $\mathbf{r}^{2}$ & $\boldsymbol{p}$ & Spectral index & $\mathbf{r}^{\mathbf{2}}$ & $\boldsymbol{p}$ \\
\hline $\mathrm{D}_{816} / \mathrm{D}_{592}$ & 0.1567 & 0.379 & $\left(\mathrm{D}_{816}-\mathrm{D}_{592}\right) /\left(\mathrm{D}_{816}+\mathrm{D}_{592}\right)$ & $\mathbf{0 . 8 3 4 1}$ & 0.004 \\
$\mathrm{D}_{816} / \mathrm{D}_{628}$ & 0.1032 & 0.482 & $\left(\mathrm{D}_{816}-\mathrm{D}_{628}\right) /\left(\mathrm{D}_{816}+\mathrm{D}_{628}\right)$ & $\mathbf{0 . 8 2 1 9}$ & 0.005 \\
$\mathrm{D}_{816} / \mathrm{D}_{851}$ & 0.7597 & 0.011 & $\left(\mathrm{D}_{816}-\mathrm{D}_{851}\right) /\left(\mathrm{D}_{816}+\mathrm{D}_{851}\right)$ & 0.2124 & 0.298 \\
$\mathrm{D}_{903} / \mathrm{D}_{592}$ & 0.7135 & 0.017 & $\left(\mathrm{D}_{903}-\mathrm{D}_{592}\right) /\left(\mathrm{D}_{903}+\mathrm{D}_{592}\right)$ & 0.032 & 0.701 \\
$\mathrm{D}_{903} / \mathrm{D}_{628}$ & 0.7462 & 0.012 & $\left(\mathrm{D}_{903}-\mathrm{D}_{628}\right) /\left(\mathrm{D}_{903}+\mathrm{D}_{628}\right)$ & 0.3708 & 0.147 \\
$\mathrm{D}_{903} / \mathrm{D}_{851}$ & 0.6714 & 0.024 & $\left(\mathrm{D}_{903}-\mathrm{D}_{851}\right) /\left(\mathrm{D}_{903}+\mathrm{D}_{851}\right)$ & $\mathbf{0 . 9 2 1 6}$ & 0.001 \\
$\mathrm{D}_{974} / \mathrm{D}_{592}$ & $\mathbf{0 . 8 0 2 1}$ & 0.006 & $\left(\mathrm{D}_{974}-\mathrm{D}_{592}\right) /\left(\mathrm{D}_{974}+\mathrm{D}_{592}\right)$ & $\mathbf{0 . 8 6 2 7}$ & 0.003 \\
$\mathrm{D}_{974} / \mathrm{D}_{628}$ & $\mathbf{0 . 8 5 2 7}$ & 0.003 & $\left(\mathrm{D}_{974-} \mathrm{D}_{628}\right) /\left(\mathrm{D}_{974}+\mathrm{D}_{628}\right)$ & $\mathbf{0 . 8 8 5 3}$ & 0.002 \\
$\mathrm{D}_{974} / \mathrm{D}_{851}$ & 0.7545 & 0.011 & $\left(\mathrm{D}_{974-\mathrm{D}_{851}}\right) /\left(\mathrm{D}_{974}+\mathrm{D}_{851}\right)$ & 0.0876 & 0.519 \\
\hline
\end{tabular}

\subsubsection{Determination of the hyperspectral indices sensitive to salt stress at the leaf level}

The hyperspectral indices sensitive to salt stress at the leaf level were determined in the same way as for the canopy level. The difference of the leaf reflectance (Figure 8) was calculated first. The correlation (Figure 9) between the original spectral reflectance difference and the different $\mathrm{NaCl}$ concentrations was then analyzed. The reflectance difference in the range of 400 $750 \mathrm{~nm}$ is positively correlated with salt stress. The highest correlation coefficient is found at the $631 \mathrm{~nm}$ wavelength. In addition, the correlation between the first-order derivative spectral reflectance difference and the different $\mathrm{NaCl}$ concentrations is clearly improved, but the correlation coefficient curve fluctuates wildly. There is a relatively high positive correlation ( $\mathrm{p}$ $<0.01$ ) in the $480-484 \mathrm{~nm}$ wavelength and a high negative correlation in the $667-670 \mathrm{~nm}$ wavelength. Overall, the correlation between the first-order derivative leaf reflectance difference of Suaeda salsa and salt stress is better than that of the original leaf reflectance difference and salt stress (Table 5). 


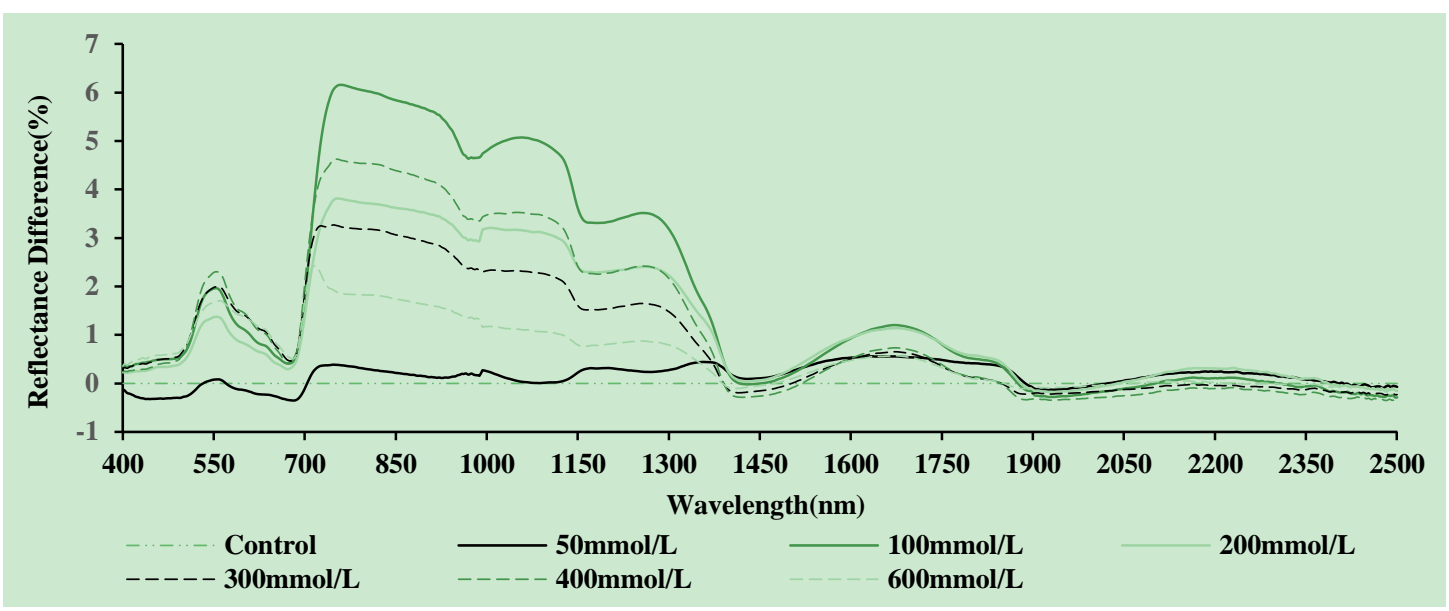

(a)

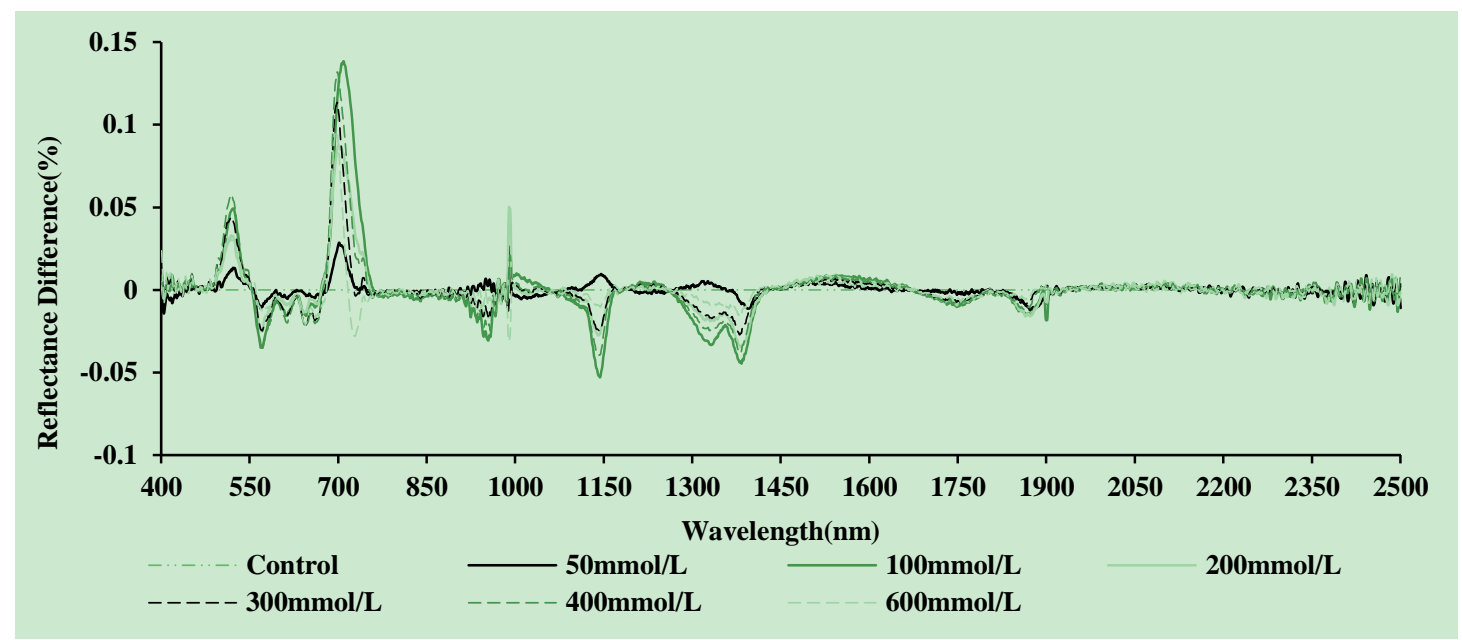

(b)

Figure 8. Reflectance difference between the original spectra (a) and the first-order derivative spectra (b) for stressed vs. non-stressed leaves throughout the $400-2,500 \mathrm{~nm}$ wavelength. The differences were computed by subtracting the mean reflectance of non-stressed leaves (zero line) from that of stressed leaves. The mean values are for three measurements $(\mathrm{N}=3)$.

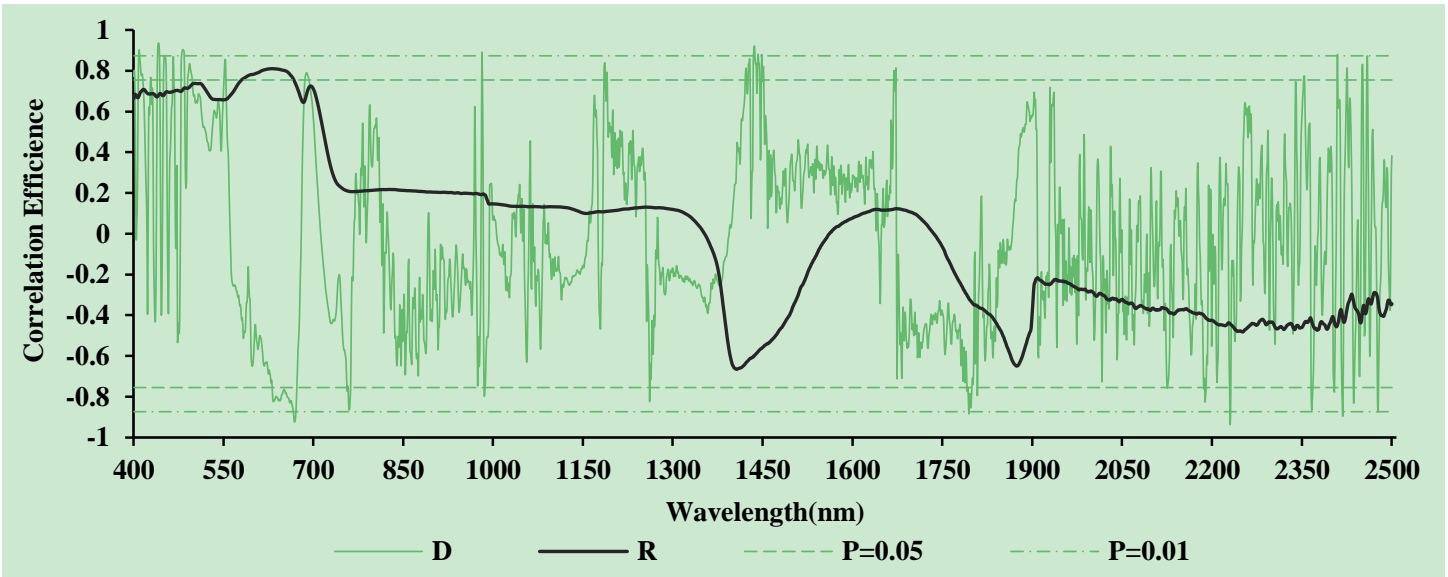


Figure 9. A plot of the correlation coefficients between the reflectance difference of the raw leaf spectra and the first-derivative spectra and salt concentration. The thick and thin lines are the curves of the reflectance difference of the original spectra and the first-derivative spectra and the salt concentration correlation coefficient, respectively.

Table 5. Wavelength ranges $(\mathrm{nm})$ for the significant reflectance differences.

\begin{tabular}{ccccc}
\hline \multirow{2}{*}{$\begin{array}{c}\text { Spectral } \\
\text { transformatio }\end{array}$} & \multicolumn{2}{c}{ r_max } & Numbe & Wavelength ranges (nm) \\
\cline { 2 - 4 } $\mathbf{n}$ & Wavelength & $\mathbf{r}$ & $\mathbf{r}$ & \\
\hline $\mathrm{R}$ & 631 & $0.810^{*}$ & 88 & $580-667$ \\
$\mathrm{D}$ & 2230 & $-0.934^{*} *$ & 23 & $409,440-442,480-484,667-670,981$, \\
& & & & $1435,1436,1442,1448,1794,2230,2409$, \\
& & & & 2418,2477
\end{tabular}

Note: ${ }^{*} \mathbf{p}<0.05, * * \mathbf{p}<0.01$

Based on the correlation analysis results, the bands in the ranges of 1335-1499 nm and 1770$2500 \mathrm{~nm}$ were removed because they are not sensitive to salt stress. Therefore, the maximum (a) and the minimum (b) of the reflectance differences are $981 \mathrm{~nm}, 484 \mathrm{~nm}, 442 \mathrm{~nm}$ and $667 \mathrm{~nm}$, $409 \mathrm{~nm}$, and $481 \mathrm{~nm}$, respectively. The RSI and NDSI indices were then constructed (Table 6). The correlation $\left(\mathrm{r}^{2}\right)$ and significance level $(\mathrm{p})$ between the spectral indices and salt stress were then obtained. It can be seen that spectral indices such as $\mathrm{D}_{442} / \mathrm{D}_{481}$ and $\left(\mathrm{D}_{442}-\mathrm{D}_{667}\right) /\left(\mathrm{D}_{442}+\mathrm{D}_{667)}\right.$ at the leaf level are the spectral indices that are sensitive to salt stress.

Table 6. Leaf spectral indices that were tested for significant $(p<0.05)$ correlation with the salt concentration

\begin{tabular}{cccccc}
\hline Spectral index. & $\mathrm{r}^{2}$ & $p$ & Spectral index & $\mathrm{r}^{2}$ & $p$ \\
\hline $\mathrm{D}_{981} / \mathrm{D}_{667}$ & -0.7405 & 0.0570 & $\left(\mathrm{D}_{981}-\mathrm{D}_{667}\right) /\left(\mathrm{D}_{981}+\mathrm{D}_{667}\right)$ & -0.875 & 0.010 \\
$\mathrm{D}_{981} / \mathrm{D}_{409}$ & 0.4215 & 0.3463 & $\left(\mathrm{D}_{981}-\mathrm{D}_{409}\right) /\left(\mathrm{D}_{981}+\mathrm{D}_{409}\right)$ & -0.033 & 0.944 \\
$\mathrm{D}_{981} / \mathrm{D}_{481}$ & 0.8197 & 0.0240 & $\left(\mathrm{D}_{981}-\mathrm{D}_{481}\right) /\left(\mathrm{D}_{981}+\mathrm{D}_{481}\right)$ & 0.427 & 0.339 \\
$\mathrm{D}_{484} / \mathrm{D}_{667}$ & -0.6784 & 0.0939 & $\left(\mathrm{D}_{484}-\mathrm{D}_{667}\right) /\left(\mathrm{D}_{484}+\mathrm{D}_{667}\right)$ & -0.606 & 0.149 \\
$\mathrm{D}_{484} / \mathrm{D}_{409}$ & 0.5306 & 0.2205 & $\left(\mathrm{D}_{484}-\mathrm{D}_{409}\right) /\left(\mathrm{D}_{484}+\mathrm{D}_{409}\right)$ & 0.258 & 0.576 \\
$\mathrm{D}_{484} / \mathrm{D}_{481}$ & 0.7807 & 0.0383 & $\left(\mathrm{D}_{484}-\mathrm{D}_{481}\right) /\left(\mathrm{D}_{484}+\mathrm{D}_{481}\right)$ & 0.173 & 0.711 \\
$\mathrm{D}_{442} / \mathrm{D}_{667}$ & -0.8536 & 0.0145 & $\left(\mathrm{D}_{442}-\mathrm{D}_{667}\right) /\left(\mathrm{D}_{442}+\mathrm{D}_{667}\right)$ & $-\mathbf{0 . 8 9 8}$ & $\mathbf{0 . 0 0 6}$ \\
$\mathrm{D}_{442} / \mathrm{D}_{409}$ & 0.7123 & 0.0725 & $\left(\mathrm{D}_{442}-\mathrm{D}_{409}\right) /\left(\mathrm{D}_{442}+\mathrm{D}_{409}\right)$ & 0.243 & 0.599 \\
$\mathrm{D}_{442} / \mathrm{D}_{481}$ & $\mathbf{0 . 8 8 8 7}$ & $\mathbf{0 . 0 0 7 5}$ & $\left(\mathrm{D}_{442}-\mathrm{D}_{481}\right) /\left(\mathrm{D}_{442}+\mathrm{D}_{481}\right)$ & 0.474 & 0.283 \\
\hline
\end{tabular}

\section{Discussion}

\subsection{Plant growth}

Soli salinity is a major abiotic stress which has a negative impact on plant growth and the ecosystem health in coastal wetlands [29]. The succulence of leaves is an important way for the 
Suaeda salsa plant to adapt to the saline environment. The specific expression is that the parenchyma cells grow a lot, and as the number of cells increases, the volume also increases. The plant can thus absorb and store a large amount of water. As a result, the water content in the unit volume of tissue increases, which can dilute the salt absorbed by the plant from the soil environment and maintain the normal physiological activities of the plant [30-33].

In our study, the FW, root length, branch number, and height of Suaeda salsa were found to increase significantly at the lower salinity levels $(0-200 \mathrm{mmol} / \mathrm{L} \mathrm{NaCl})$ and then decrease slightly at the higher salinity levels $(>200 \mathrm{mmol} / \mathrm{L} \mathrm{NaCl}$ ). This finding is in agreement with Jia et al. (2018) [34], who studied the effects of drought and salt stress on the growth characteristics of Suaeda salsa in coastal wetlands and indicated that the FW, DW, and height of Suaeda salsa increased at lower salinity levels but decreased at higher salinity levels. The finding also agrees with Song et al. (2011) [35], who found that the dry shoot weight of two Suaeda salsa populations first increased and then decreased with the increasing salinity level. In addition, we found that the FW, root length, branch number, and height peaked at the $200 \mathrm{mmol} / \mathrm{L}$ salt level. This is consistent with the finding of Peng et al. (2016) [36], who indicated that the FW, DW, and succulence of the Suaeda salsa plant under the $200 \mathrm{mmol} / \mathrm{L} \mathrm{NaCl}$ treatment increased greatly compared with the control.

\subsection{Leaf pigment content}

The chlorophyll content is one of the important physiological responses to salt stress. Salt stress may lead to thylakoid enlargement of chloroplast and irregular arrangement of grana. In our study, it was found that the low salinity level of $50 \mathrm{mmol} / \mathrm{L}$ can promote the absorption of water and the nutrients in the soil. It can also improve the synthesis of chlorophyll, the photosynthetic efficiency, and the metabolic activity in Suaeda salsa. At the high salinity level of $600 \mathrm{mmol} / \mathrm{L}$, we found that the chl-a content, chl-b content, total chlorophyll content, and carotenoid content were at the minimum values. Several researchers such as Guan et al. (2011) [11] and Ma. (2004) [28] have also found that the chlorophyll content reduces with the increasing $\mathrm{NaCl}$ concentration. However, Guan et al. (2011) [11] found that the leaf chlorophyll content was the highest at the $0 \%$ salt level and a water table of -20 and $-30 \mathrm{~cm}$, which is not consistent with our research findings. Nevertheless, our study is in agreement with Guan et al. (2011) [11], in that they also indicated that the chlorophyll content was the lowest at the highest salt stress. However, Lu et al. (2002) [37] concluded that salt stress had no effects on the neoxanthin, lutein, $\beta$-carotene, violaxanthin, antheraxanthin, zeaxanthin, chl-a, and chl-b contents. These contradictory findings may have been be caused by the experimental conditions of different $\mathrm{NaCl}$ concentrations, high light levels, plant types, salt types, and salt concentrations.

\subsection{Hyperspectral indices sensitive to salt stress}

The growth of a plant is hampered when it is subject to one or several stresses. One of the most important occurrences is a decrease in chlorophyll content. Once the chlorophyll content decreases, the absorption is reduced and the reflectance is increased in the blue and red wavelengths. In the present study, for the halophyte Suaeda salsa, it was found that the control without salinity and the highest salt stress both cause increased raw reflectance in the 400$680 \mathrm{~nm}$ wavelength. Zhang et al. (2012) [17] found that salinity stress affected the hyperspectral 
canopy reflectance in Suaeda salsa L. and the raw reflectance in the 400-1,000 $\mathrm{nm}$ spectral region in the order of low salinity $>$ mid salinity $>$ high salinity. However, we found that Zhang et al. did not analyze in detail the soil salt content in the study area or the thresholds of the low, mid, and high salinity levels. Therefore, we believe that these are the main reasons for the raw reflectance differences under different salinity stress levels.

Hamzeh et al. (2013) [27] utilized 24 vegetation indices extracted from Hyperion satellite imagery to estimate the soil salinity in sugarcane fields, where these vegetation indices were formulated based on a combination of chlorophyll and water absorption bands. However, Hamzeh et al. (2013) [27] did not consider in detail the soil salt content and only analyzed the correlation between the salt content and vegetation indices, while constructing the estimation models for soil salinity by the use of 60 soil samples and validating them by 48 soil samples. In the present study, the use of only 21 pot experiments under seven different salinity stress levels was not enough to identify the salinity stress by the above method. In order to explain the change of the reflectance spectra of Suaeda salsa caused by the different $\mathrm{NaCl}$ concentrations compared with the control group, we utilized the ratios of the canopy leaf reflectance sensitive to the salinity stress. Carter (1993) [29] indicated that the maximum sensitivity of reflectance to stress generally occurred within the 535-640 nm and 685-700 nm ranges. Carter (1994) [26] found that the ratios of $R_{695} / R_{420}, R_{605} / R_{760}, R_{695} / R_{760}$ and $R_{710} / R_{760}$ were significantly greater in stressed compared with non-stressed leaves for eight stress agents among six plant species. However, in this study, we found that (D903-D851)/(D903+D851), (D974- $\left.\mathrm{D}_{628}\right) /\left(\mathrm{D}_{974}+\mathrm{D}_{628}\right)$,

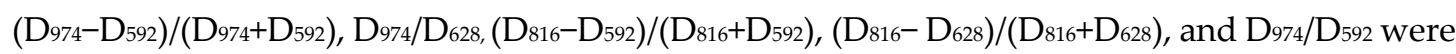
the spectral indices that were sensitive to salt stress. The difference was likely caused by the stress agents and plant species.

\section{Conclusions}

The results of this study showed that soil salinity stress in 21 Suaeda salsa pot experiments has an effect on the physiological indicators and reflectance spectra. For this purpose, the qualitive and quantitative impacts of salinity stress on the growth of Suaeda salsa were investigated and the hyperspectral indices sensitive to salinity stress were extracted from the narrow bands.

The physiological indicators such as plant height, root length, leaf succulence, relative water content of Suaeda salsa above the ground achieve the maximum values at the $200 \mathrm{mmol} / \mathrm{L}$ $\mathrm{NaCl}$ salinity. The chlorophyll content Suaeda salsa peaked at the $50 \mathrm{mmol} / \mathrm{L} \mathrm{NaCl}$ salinity and got the minimum value at the $600 \mathrm{mmol} / \mathrm{L}$. These changes on the physiological indicators of Suaeda salsa caused by salt stress inevitably have some impacts on the reflectance spectra at both the leaf and canopy level. Sensitive hyperspectral indices to salt stress were retrieved by the ANOVA analysis. The most sensitive indices to salt stress at both the leaf and canopy levels were $\left(\mathrm{D}_{442}-\mathrm{D}_{667}\right) /\left(\mathrm{D}_{442}+\mathrm{D}_{667}\right)$ and $\left(\mathrm{D}_{903}-\mathrm{D}_{851}\right) /\left(\mathrm{D}_{903}+\mathrm{D}_{851}\right)$ respectively.

In this paper, we have only discussed the impact of salinity stress on the growth and reflectance spectra of Suaeda salsa. In the future, it will be necessary to consider the impacts of multiple stress agents, such as salt stress, waterlogging, and the water table, on the growth and reflectance spectra of Suaeda salsa, in order to establish the hyperspectral response mechanism of Suaeda salsa to multiple stress agents. 
Author Contributions: Experiment, R.W., Y.L.L., Y.R.L. and Z.Y.; Methodology, X.L., Y.T. and S.Z.; Writing-Original draft, X.L. , S.Z., and Y.Z.; Writing-Review \& editing, X.L., and Y.Z.; Improving the data analysis, X.L. and S.Z.

Funding: This study was financially supported by the National Natural Science Foundation (no. 41506106); a project funded by the Priority Academic Program Development of Jiangsu Higher Education Institutions (PAPD) and the Foundation of Key Laboratory for Geo-Environmental Monitoring of Coastal Zone of the National Administration of Surveying, Mapping and Geo-information (No.GE-2017-003); the Marine Technology Brand Specialty Construction Project of Jiangsu Province (No. PPZY2015B116); and the Postgraduate Research \& Practice Innovation Program of Jiangsu province (SJCX19_0962).

Conflicts of Interest: The authors declare no conflict of interest.

\section{References}

1. Liu, X. H. Effects of salinity and hydrological interference on individuals and populations of Suaeda salsa. Master's thesis, Shandong: Shandong Normal University. 2016.

2. Cui, B., He, Q., Zhao, X. Ecological thresholds of Suaeda salsa to the environmental gradients of water table depth and soil salinity. Acta Ecol. Sin. 2008, 28 (4), 1408-1418.

3. Zheng, C., Jiang, D., Liu, F., Dai, T., Jing, Q., Cao, W. Effects of salt and waterlogging stresses and their combination on leaf photosynthesis, chloroplast ATP synthesis, and antioxidant capacity in wheat. Plant Sci. 2009, 176, 575-582.

4. Saqib, M., Akhtar, J., Qureshi, R. H. $\mathrm{Na}^{+}$exclusion and salt resistance of wheat (Triticumaestivum) in saline-waterlogged conditions are improved by the development of adventitious nodal roots and cortical root aerenchyma. Plant Sci. 2005, 169 (1), 125-130.

5. Cui, B., He, Q., Zhao, Z. Ecological thresholds of Suaeda salsa to the environmental gradients of water table depth and soil salinity. Acta Ecol. Sin. 2008, 28(4), 1408-1418.

6. Wang, B. S., Luttge, U., Ratajczak, R. Specific regulation of SOD isoforms by $\mathrm{NaCl}$ and osmotic stress in leaves of the $C_{3}$ halophyte Suaeda salsa L. J. Plant Physiol. 2004, 161 (3), 285293.

7. Zhang, L. B., Xu, H. L., Zhao, G. X. Salt tolerance of Suaeda salsa and its soil ameliorating effect on coastal saline soil. Soils. 2007, 39(2), 310-313.

8. Lin, X. Z., Chen, K. S., He, P. Q., Shen, J. H., Huang, X. H. The effects of Suaeda salsa L planting on the soil microflora in coastal saline soil. Act Ecologica Sinica. 2006, 26 (1), 801807.

9. Xin, Q., Liu, C., Liu, Y., Wang Y., Wei, H., Li, J. Secretion of total organic carbon and inorganic carbon from roots of seepweed Suaeda heteroptera in response to Zn (II) stress. Chin J Appl Environ Biol. 2014, 20 (1), 134-138.

10. Mao, P., Cheng, W., Liu, Y., Wang, G., Chen, J., Han, G., Zhang, Z., Yu, J., Liu, F. Biomass allocation in Suaeda salsa population in different habitats of coastal zone. Ecology and Environmental Sciences. 2011, 20 (8-9), 1214-1220.

11. Guan, B., Yu, J., Wang, X., Fu, Y., Kan, X., Lin, Q., Han, G., Lu, Z. Physiological responses of halophyte Suaeda salsa to water table and salt stresses in coastal wetland of Yellow River delta. Clean Soil Air Water. 2011, 39 (12), 1029-1035.

12. Cui, B.S., Zhao, X.S., Yang, Z.F. The response of reed community to the environment gradient of water depth in the Yellow River Delta. Acta Ecol. Sin. 2006, 26, 1154-1533.

13. Xiong, X., He, Q., Cui, B. S., Ecol, C. J. Double principal coordinate analysis of herbaceous vegetation in wetlands of the Yellow River Delta, China. Chin. J. Ecol. 2008, 27, 1631-1638.

14. Song, C. Y., Liu, G. Y., Liu, Q. S., Cao, M. C., Huang, C. Distribution patterns of plant communities in the Yellow River Delta and related affecting factors. Chin. J. Ecol. 2008, 27, 2042-2048.

15. He, Q., Cui, B. S., Zhao, X. S., Fu, H. L., Liao, X. L. Relationships between salt marsh vegetation distribution/diversity and soil chemical factors in the Yellow River Estuary, 
China. Acta Ecol. Sin. 2009, 29(2), 676-687.

16. Yu, J., Chen, X., Sun, Z., Xie, W., Mao, P., Wu, C., Dong, H. The spatial distribution characteristics of soil nutrients in new-born coastal wetland in Yellow River delta. Acta Sci. Circum. 2010, 30 (4), 855-861.

17. Zhang, G.S., Wang, R.Q., Song, B. M. Plant community succession in modern Yellow River Delta, China. J. Zhejiang Univ. Sci. 2007, 8(08), 540-548.

18. Zhang, H., Hu, H., Zhang, X.B., Wang, K.L., Song, T.Q., Zeng, F. P. Detecting Suaeda salsa $L$. chlorophyll fluorescence response to salinity stress by using hyperspectral reflectance. Acta Physiol. Plant. 2012, (34), 581-588.

19. Wang, J. B., Zhang, J., Ma, Y., Ren, G. B. Classification method of hyperspectral image in typical surface feature of Huanghe River estuary wetland. Journal of Marine Sciences. 2014, $32(3), 36-41$.

20. Liu, Q. S., Zhang, M., Ning, J. C., Liu, G. H., Fu, X., Huang, C. Hyperspectral vegetation indices of Suaeda Salsa in response to changes of soil chemical properties. Geography and Geo-Information Science. 2011, 27 (3), 86-90.

21. Ren, G. B., Zhang, J., Ma, Y. Spectral discrimination and separable feature lookup table of typical vegetation species in Yellow River Delta wetland. Marine Environmental science. 2015, 34 (3), 420-426.

22. Wu, T., Zhao, D. Z., Kang, J. C., Suo, A. N., Wei, B. Q., Ma, Y. J. Research on remote sensing inversion biomass method based on the Suaeda Salsa' s measured spectrum. Spectrosc. Spect. Anal. 2010, 30 (5), 1336-1341.

23. Lu, X., Sun, H., Yu, Y., Wang, Y., Yang, J., Zhang, L. The estimation model of biomass of Suaeda Salsa in coastal wetland based on hyperspectral reflectance spectra. Transactions of oceanology and limnology. 2017, 2, 96-100.

24. Zhao, X. L., Lin, Y., Zhang, G. F., Xie, S. B., Hua, W. J., Ding, Y. H. Community characteristics of beach wetland vegetations along a habitat gradient in Dafeng Milu Reserve of Jiangsu Province. Chinese Journal of Ecology. 2010, 29(2), 244-249.

25. Duan, D. Y., Li, W. Q., Liu, X. J., Yang, H., An, P. Seed germination and seedling growth of Suaeda salsa under salt stress. Annales Botanici Fennici. 2007, 44(3), 161-169.

26. Carter, G. A. Ratios of leaf reflectance in narrow wavebands as indicators of plant stress. International Journal of Remote Sensing. 1994, 15(3), 697-703.

27. Hamzeh S., Naseri A.A., AlaviPanah S.K., Mojaradi B., Bartholomeus H. M., Clevers J. G. P. W., Behzad M. Estimating salinity stress in sugarcane fields with spaceborne hyperspectral vegetation indices. International Journal of Applied Earth Observation and Geoinformation. 2013, 21, 282-290.

28. Ma, D. J. Studies on effects of some halophytes under salt stress. Master's thesis, Xin Jiang: Xinjiang University. 2004.

29. Carter G.A. Responses of leaf spectral reflectance to plant stress. American Journal of Botany, 1993, (80), 239-243.

30. Zhang, A. Q., Pang, Q. Y., Yan, X. F. Advances in salt-tolerance mechanisms of Suaeda plants. Acta Ecologica Sinica. 2013, 33(12), 3575-3583.

31. Jennings, D. H. Halophytes, succulence and sodium in plants-a unified theory. New Phytologist. 1968, 67(4), 899-911.

32. Eshel, A. Response of Suaeda aegyptiaca to $\mathrm{KCl}, \mathrm{NaCl}$ and $\mathrm{Na}_{2} \mathrm{SO}_{4}$ treatments. Physiologia Plantarum. 1985, 64(3), 308-315.

33. Khan, M. A., Ungar, I. A., Showalter, A. M. The effect of salinity on the growth, water status, and ion content of a leaf succulent perennial halophyte, Suaeda fruticose (L.) Forssk. Journal of Arid Environments. 2000, 45(1), 73-84.

34. Jia, J., Huang, C., Bai, J., Zhang, G., Zhao, Q., Wen, X. Effects of drought and salt stresses on growth characteristics of euhalophyte Suaeda salsa in coastal wetlands. Physics and Chemistry of the Earth. 2018, 103, 68-74. 
35. Song, J., Shi, G. W., Gao, B., Fan, H., Wang, B. S. Waterlogging and salinity effects on the two Suaeda salsa populations. Physiol. Plant. 2011, 141(4), 343-351.

36. Peng, B., Xu, W., Shao, R., Feng, G., Shi, W. Growth of Suaeda salsa tin response to salt stress in different habitats. Acta Prataculturae Sinica. 2016, 25(4), 81-90.

37. Lu, C., Qiu, N., Lu, Q., Wang, B., Kuang T. Does salt stress lead to increased susceptibility of photosystem II to photoinhibition and changes in photosynthetic pigment composition in halophyte Suaeda salsa grown outdoors? Plant Science. 2002, (163), 1063-1068. 